\title{
UNDERSTANDING THE INITIAL REQUIREMENTS DEFINITION IN EARLY DESIGN PHASES
}

\author{
Song, Young-Woo; Herzog, Michael; Bender, Beate \\ Ruhr-Universität Bochum, Chair of Product Development
}

\begin{abstract}
The definition of initial requirements in the early phase of product development is characterised as a decision process under highest uncertainties. Studies show that projects often deviate from their planned goals or even fail due to ill-defined requirements. Despite the importance and criticality of this task, a detailed description and risk-oriented explanation is missing in the product development literature. The goal of this paper is to develop an explanation model/frame which establishes a link between the development context and an appropriate procedure for the initial requirements definition based on general risk treatment strategies. In a first step, risk-driving context factors with high influence on this task are identified. Then two case studies are compared to analyse the interrelations between their context factors and the applied risk treatment strategies that are implemented in their procedures for defining initial requirements.
\end{abstract}

Keywords: Requirements, Early design phases, Risk management, Case study

\section{Contact:}

Song, Young-Woo

Ruhr-Universität Bochum

Chair of product development

Germany

song@lpe.rub.de 


\section{INTRODUCTION}

The increasing competition forces companies to launch innovative products to market in ever shorter times and under great cost pressure. Objectives in this tension field must be translated into clear requirements that serve as a common information basis for all employees involved in the development process and for the verification of the outcome afterwards. Aware of this central role in the development process influential procedure models (e.g. Pahl et al., 2007; Cross, 2000; Ulrich and Eppinger, 1995) share the common assumption to start engineering design with the definition of requirements in order to clarify and specify the development task. But these textbooks lack a detailed description of this phase (Chakrabarti et al., 2004) and create the impression that requirements definition should be largely completed prior to the systematic search for design solutions (Hansen and Andreasen, 2007). However, understanding product development as a process of gaining and processing information (Ehrlenspiel and Meerkamm, 2017), the requirements list concretises with the progress of the development which is also known as co-evolution of requirements/problem and solutions (Nidamarthi et al., 1997). Therefore, Feldhusen and Grote (2013) distinguish between initial requirements, which strongly influence the concept and must be defined in the early stage, and detail requirements, which are developed in parallel with concretisation of the solution.

Whereas recent research achieved findings about the second type (e.g. Chakrabarti et al., 2004; Hansen and Andreasen, 2007; Sudin and Ahmed-Kristensen, 2011; Albers et al., 2012, 2016) this paper focuses on the definition of initial requirements. As studies repeatedly show, ill-defined requirements in the early stage are identified as particularly significant causes for product development projects to often deviate from their planned goals or to be considered a failure (Bullinger et al., 2003; Engel et al., 2008; Rietiker et al., 2013; Jakoby, 2015). Inaccurate planning based on incorrect requirements would regularly lead to intensive 'firefighting' in order to realise the required quality of results in time. The observed discrepancies between definition and implementation of requirements result from the pressure to innovate and its associated risks due to the lack of knowledge and information in this early stage. That leads to the contradicting demand to set ambitious but feasible goals (Eiletz, 1999). So, defining initial requirements means finding a right compromise between the achievable customer benefit and the affordable development effort (Song et al., 2018). But in every case, it depends on the development context, the specific goals and boundary conditions as well as the existing uncertainties and risks to decide individually where this compromise lies and how to proceed to find it.

On that background our paper aims at contributing to a deeper understanding of the interrelation between different risky development contexts and different risk-oriented procedures for the initial requirements definition. This paper is structured into four sections according to the Design Research Methodology by Blessing and Chakrabarti (2009). The foundations to clarify our understanding of this situation (research clarification), general strategies to support the treatment of risks and the influence of the context on product development processes are described in section 2 (descriptive study I). Based on that, section 3 sets the frame for an explanation model (prescriptive study), which is exemplified with two case studies that indicate interrelations between the context and strategies/approaches for the initial requirements definition (descriptive study II). The further purpose of our explanation model/frame is the development of a methodical support for development teams to design an own context specific procedure in a systematic and conscious manner. This will be discussed in the last section.

\section{RESEARCH CLARIFICATION / STATE OF THE ART}

\subsection{Modest low-risk goals vs. ambitious high-risk goals}

Innovation is the result of a renewal process that either extends existing knowledge or applies available knowledge to a new context (Ericson and Kastensson, 2011). However, the development of innovative products is inherently fraught with risks (de Weck et al., 2007). Risks arise on the one hand, because forecasts of the innovation's benefit can deviate from the customer's actual perception after finalisation and market launch of the product. On the other hand, risks are inherent in the realisation of the product idea, since both the technical and economic feasibility of the product are not yet fully verified in the early stages of product development. Due to the complexity of the desired product, its development is rather characterised as a problem-solving-process with many iterations where new information is gained and implemented (Pahl et al., 2007; Feldhusen and Grote, 2013; 
Ehrlenspiel and Meerkamm, 2017). Costs and time requirements are also difficult to calculate on beforehand since new development activities, methods and tools might be required (Stockstrom and Herstatt, 2008). So, these risks result in the early stage from uncertainties which are understood as a consequence of insufficient experience and missing knowledge and information (Hastings and McManus, 2006). The dilemma in product development (figure 1, left-hand side) is, that despite the high uncertainties, central decisions about the design must be made as early as possible since the costs of changes increase with ongoing development progress (Ehrlenspiel and Meerkamm, 2017). Regarding this highly decisive role for the whole development process, Badke-Schaub and Frankenberger (2004) declare the initial requirements definition as a critical situation. Criticality can be understood as synonymous with risk, because the course of these situations can have negative (or positive) impacts on the objectives of the development process and/or on the result.
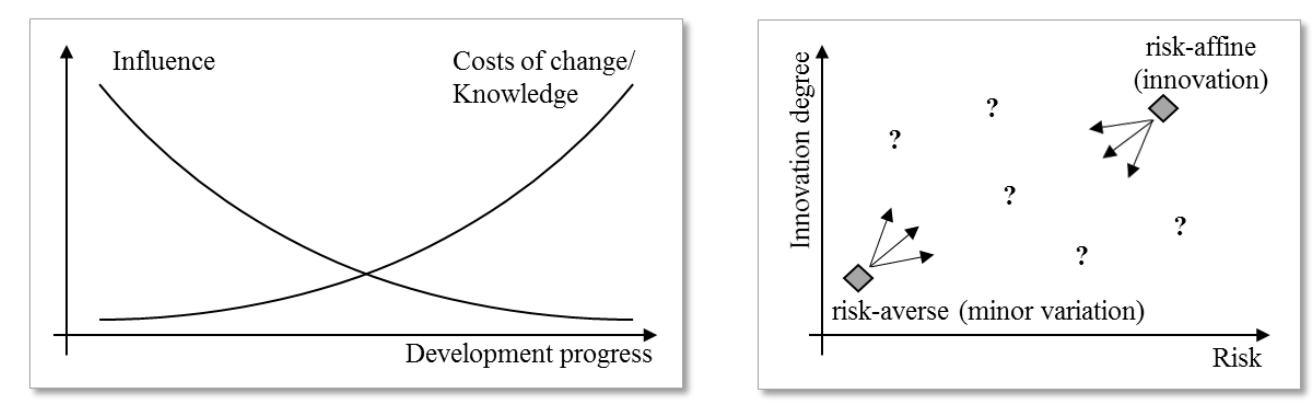

Figure 1. The paradox of product development (Ehrlenspiel and Meerkamm, 2017) (lefthand side); compromise between modest and ambitious requirements (right-hand side)

This shows a direct correlation between the level of risk and the degree of novelty of any innovative product. This correlation also shows that the risk increases the more ambitious the objective of the development project is. But on the other hand, it is also obvious that a causal correlation between the degree of novelty of an innovation and its economic potential can be assumed, because a higher degree of novelty also promises a correspondingly higher increase of the customer benefit.

Dealing with this dilemma can be observed in two opposing strategies in industrial practice. With the goal to consciously avoid risks, companies either reuse proven product structures and solution elements (Wyatt et al., 2009; Jarratt et al., 2010; Albers et al., 2015). Especially complex products are generally created through incremental modifications of solutions which matured over several product generations (Eckert et al., 2010). This is described by Albers et al. (2015) as product generation development. But as a result, the degree of innovation and thus the economic potential are relatively low (Vajna, 2014). On the opposite, less risk-averse companies often set their requirements too high, so in case of occurring risks their innovation projects remain unprofitable and can end with a total loss of investment in the worst case (Cooper, 2002). Very ambitious requirements may be easy to fulfil in isolation, but several ambitious requirements are critical when dealt with simultaneously, because conflicts emerge in their realisation when the solution to one requirement prohibits implementing the other (Salado and Nilchiani, 2016). So, if the reuse of a basic solution limits conflict resolution by creating innovations (e.g. using TRIZ), requirements must be prioritised, and compromises must be found actively in the definition phase. Assumingly, a suitable compromise must be found between innovation leap on the one hand and acceptable risk on the other hand (figure 1, right-hand side).

\subsection{Risk treatment in initial requirements definition}

The biggest challenge in the initial requirements definition is to deal with high uncertainties and resulting risks. General handling approaches can be oriented on treatment strategies from risk management. Risk management is an important element in product development that aims at ensuring the successful execution of projects and at preventing from missing time, cost and quality targets (Oehmen et al., 2010). For this purpose, various process models have been developed which differ in their number of process steps and level of detail, but all contain the treatment of risks as one key phase amongst the identification, assessment and monitoring of risks (Gericke, 2011). Based on an effect ${ }^{1}$-based understanding, risk describes the

\footnotetext{
${ }^{1}$ In contrast, a cause-based interpretation of risk refers to the unpredictability of the future and the occurrence of disruptions (Gleißner, 2011).
} 
assessed consequences of an uncertainty and thus can be quantified by uncertainty as the likelihood for an incident and its expected impact (Browning, 1998; Neumann and Bender, 2016). Consequently, the treatment of risk aims at mitigating the cause and/or the impact of an uncertainty. Based on that, the following four general strategies are usually distinguished (Kendrick, 2015; Patzak und Rattay, 2018; Gericke, 2011): avoidance (avoiding risks by reorganisation or modification), transfer (sharing risks with other stakeholders or insurances), reduction (initiating measures to mitigate/control the consequences) and acceptance (risks are known, but no measures are initiated). Avoidance is a preventive strategy that eliminates or reduces the likelihood of an incident even occurring by removing the cause. Transfer and reduction are corrective strategies, which can be further differentiated in proactive and reactive depending on the point of time at which the treatment to handle the impact is selected. A proactive strategy selects measures before a risk occurs, whereby the implementation of the measure can be done before or after the risk occurs. Contrarily, reactive strategies select and implement measures after a risk occurs. (Gericke, 2011)

The selection of an appropriate risk treatment strategy is influenced by the context, e.g. the corporate risk culture, the willingness to take risks, the risk tolerance of the team, the company's processes or capabilities (cf. Kerzner 2006). Also, the whole decision on the right compromise depends on the priorities in the specific development context (Song et al., 2018).

\subsection{The development context}

The degree of risk-aversity/affinity and thereby the requirements definition is influenced by the context of the development project. The development context is described "as a set of factors influencing the properties of the product being designed and the design process at a certain moment" (Reymen, 2001). Referring to Gericke et al. (2013) the term context factor is used for the factors, that influence the course of a development project and are described as the specific objectives and boundary conditions of a development situation. Frankenberger (1997) proposes an explanatory model that focuses on the influence of the context on critical development situations as the initial requirements definition. It emphasises thereby that of the occurrence, course and impact of this situation depends on different contexts. This model differentiates context factors from the task, the individuals, the group and the external and organisational conditions that influence the design process and its result (figure 2). This model is used as the basic frame for our investigation of possible procedures for the initial requirements definition depending on different contexts.

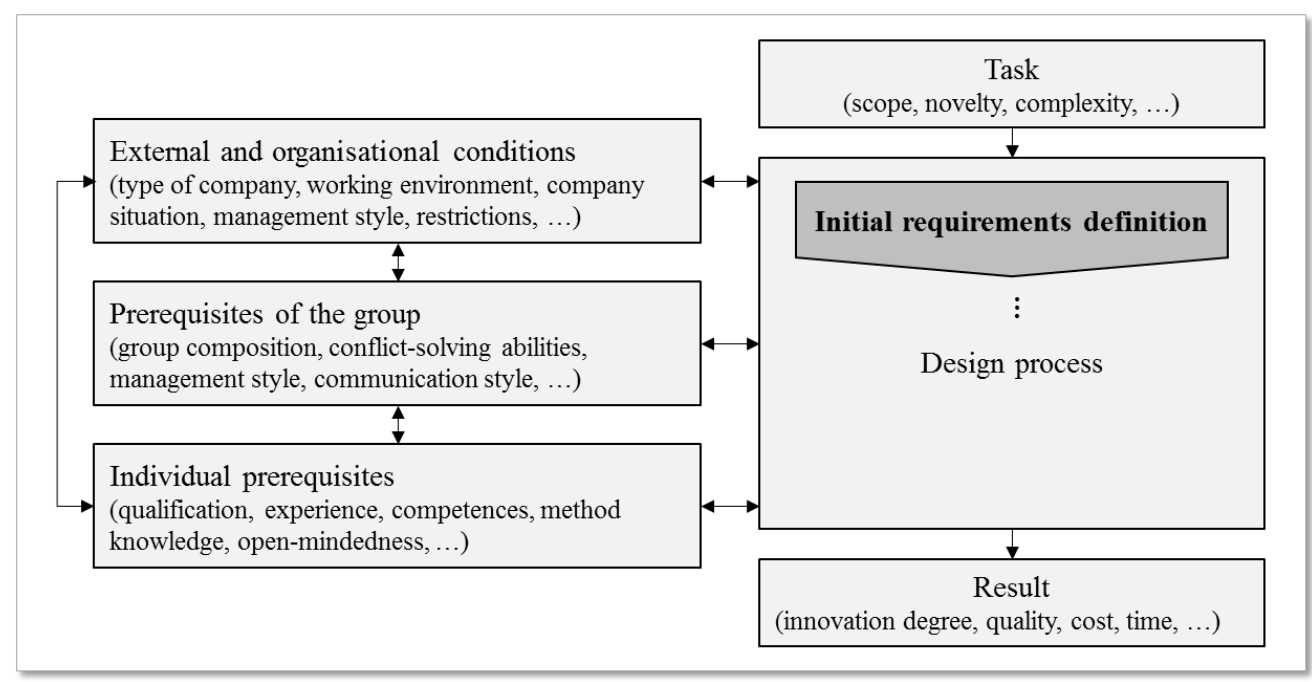

Figure 2. Model of the initial requirements definition as a critical development situation according to (Frankenberger, 1997)

In a comprehensive literature study, which contains the context factors of Frankenberger's model, Gericke et al. (2013) present a scheme of 239 context factors in total that have been identified as having influence on development projects. The context factors are categorized according to the five levels of resolution (macroeconomic, microeconomic, corporate, project and personnel) proposed by Hales and Gooch (2004). These context factors can also be allocated to the categories of Frankenberger's model (see figure 3). 


\subsection{Interim conclusion and research questions}

The definition of initial requirements is affected by high uncertainties. Depending on the resulting risks and on the development context, different risk treatment strategies can be followed in the requirements definition. But detailed descriptions cannot be found in literature. Therefore, the next section aims at answering the following research questions:

1. Which context factors significantly influence the definition of requirements? (sect. 3.1)

2. How can the definition of initial requirements be proceeded depending on the context exemplary in two cases? (sect. 3.2)

3. Which risk treatment strategies are applied in the analysed contexts and why? (sect. 3.3)

\section{ANALYSIS OF CONTEXTSPECIFIC INITIAL REQUIREMENTS DEFINITION}

\subsection{Explanation model/frame with influencing and risk-driving context factors}

For the concretisation of the explanation model/frame of the initial requirements definition, it has to be identified, which context factors have a significant influence on this development situation.

Therefor a study was conducted to sample the influencing context factors on this development situation named in literature. From the 239 context factors for the entire development process according to Gericke et al. (2013), 77 have been identified as significantly influencing on requirements definition. These are gathered from studies of Ahrens (2000), Badke-Schaub and Frankenberger (2004) and Muschik (2009) and are listed in 'level 3' of figure 3. Ahrens (2000) analyses and evaluates methods for the support of requirements elicitation and management regarding their applicability. Therefor she defines factors that influence this development situation and categorises them into: customers, transformation of customer needs into requirements, concretisation of the development task, management of requirements, competition, flexibility of the process and quality, time and cost constraints. Muschik (2009) conducted a comprehensive case study to analyse the development of the system of objectives in the early stage. As a partial result she identified influences on the decision process in this case coming from project constraints, prior knowledge and experience, degree of systematic conduction of procedures, degree of standardisation, and transparency, reliability, availability of processes and information. Furthermore, we included the context factors stated by Badke-Schaub and Frankenberger (2004), which are proposed to consider when using Frankenberger's model (see sect. 2.3) for analysing requirements definition as a critical situation.

The second part of the study concerned the context factors which are assessed in the literature as particularly risk-driving. The hypothesis is that these context factors mainly influence the decision on the compromise between modest and ambitious requirements and the process of requirements definition. The works of de Weck et al. (2007), Oehmen (2016) and Porter (1997) served to identify which of the 77 context factors from the first study-part are particularly risk-driving. De Weck et al. (2007) classify uncertainties that are often encountered and should be considered in early product and system design. They are differentiated according to whether their source is endogenous or exogenous. Both sources of uncertainty are further detailed in five context clusters which are considered exemplary and overlap each other: endogenous sources are differentiated in a product context and a corporate context, whereas the use context, the market context and the political and cultural context are mainly exogenous. In the risk management literature, hardly any risk-driving context factor in requirements definition is explicitly named. Therefore, only the risk sources for the quality of requirements mentioned by Oehmen (2016) were added to our list. Furthermore, Porter (1997) argues that risks of the product to be defined are highly determined by the company's competitive strategy. He identified three 'generic competitive strategies' in order to be successful on the market: cost leadership, differentiation and focus. Cost leadership aims at providing the product or service to the customer at the lowest possible price. Contrary to that, differentiation aims at developing a significant aspect of the product (e.g. technology, features, innovation, brand image and identity) to a quality level higher than the competitors. The focus strategy may be seen as a variation of the differentiation strategy that targets the product towards the needs of a highly specific market segment. In many branches, applying either one or another generic strategy might not be appropriate to cope with the increasingly globalised markets. Instead, hybrid strategies between both extrema, low cost and differentiation, are often necessary that allows for the pursuit of multiple objectives, as e.g. mass customisation (Winkler and Slamanig, 2009). 
However, Porter's generic competitive strategies emphasise that they are associated with different risks. For cost leadership, economy and efficiency are pursuit in all business operations, which means also minimising running cost and investment in subordinate processes. Therefore, only basic improvements would be defined in order to avoid the risk of cost-intensive iterations due to ambitious requirements. On the opposite, high investment must be risked in order to realise a quality level high enough for differentiation against competitors. Their consideration determines the product specific compromise between ambitious (differentiation-tendency) and modest (cost leadership-tendency) requirements.

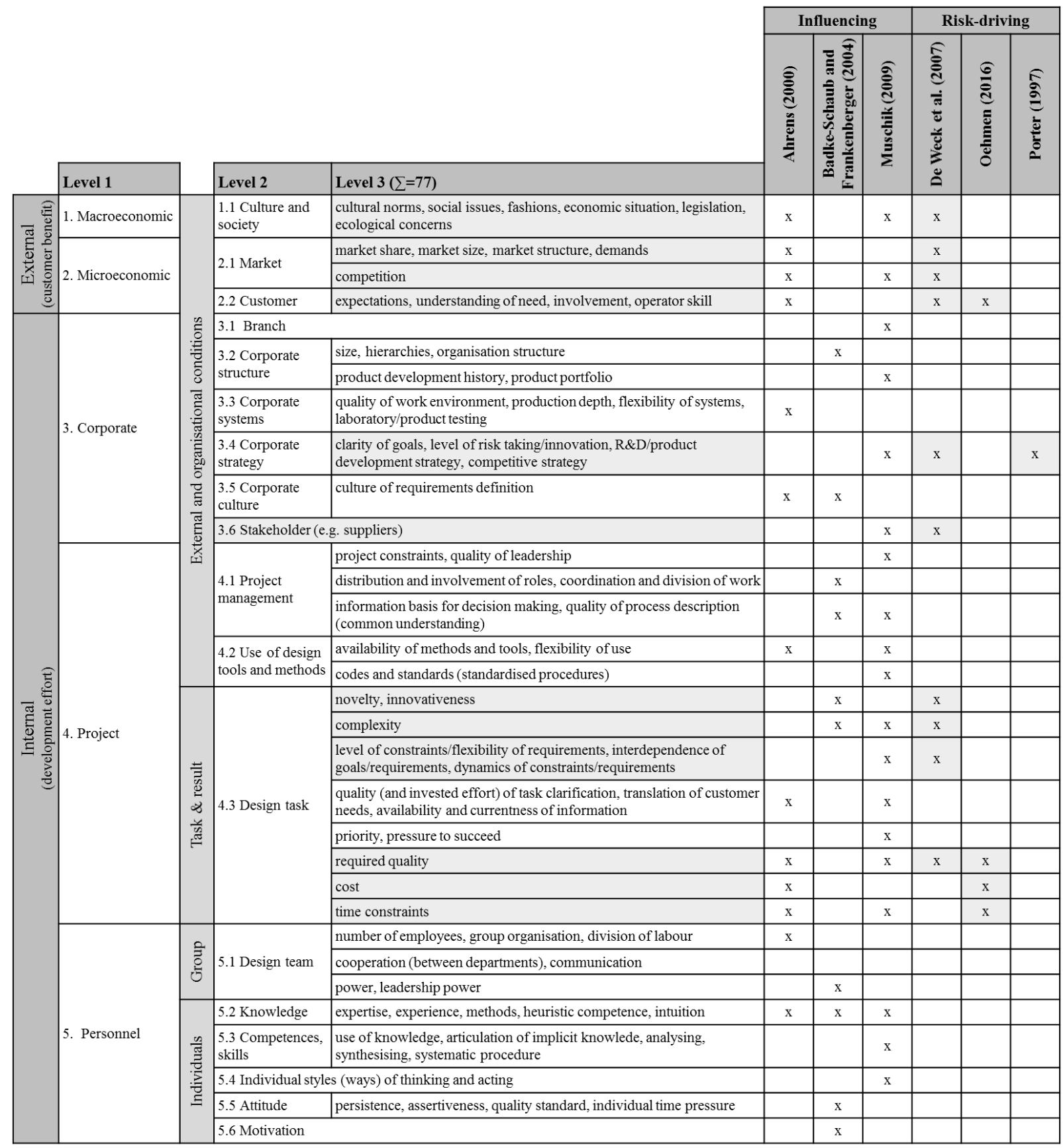

Figure 3. Context factors with significant influence on requirements definition and with high risk potential

The remaining 29 context factors are now allocated to the categories in Frankenberger's explanation model in order to concretise it for the initial requirements definition (figure 4).

Depending on the characteristics of these context factors, different procedures are possible in this development situation. For example, Porter's generic competitive strategies would trigger a procedure that follows a preventive risk treatment strategy. But also further procedures, that follow a proactive, reactive or acceptance strategy, are conceivable. 


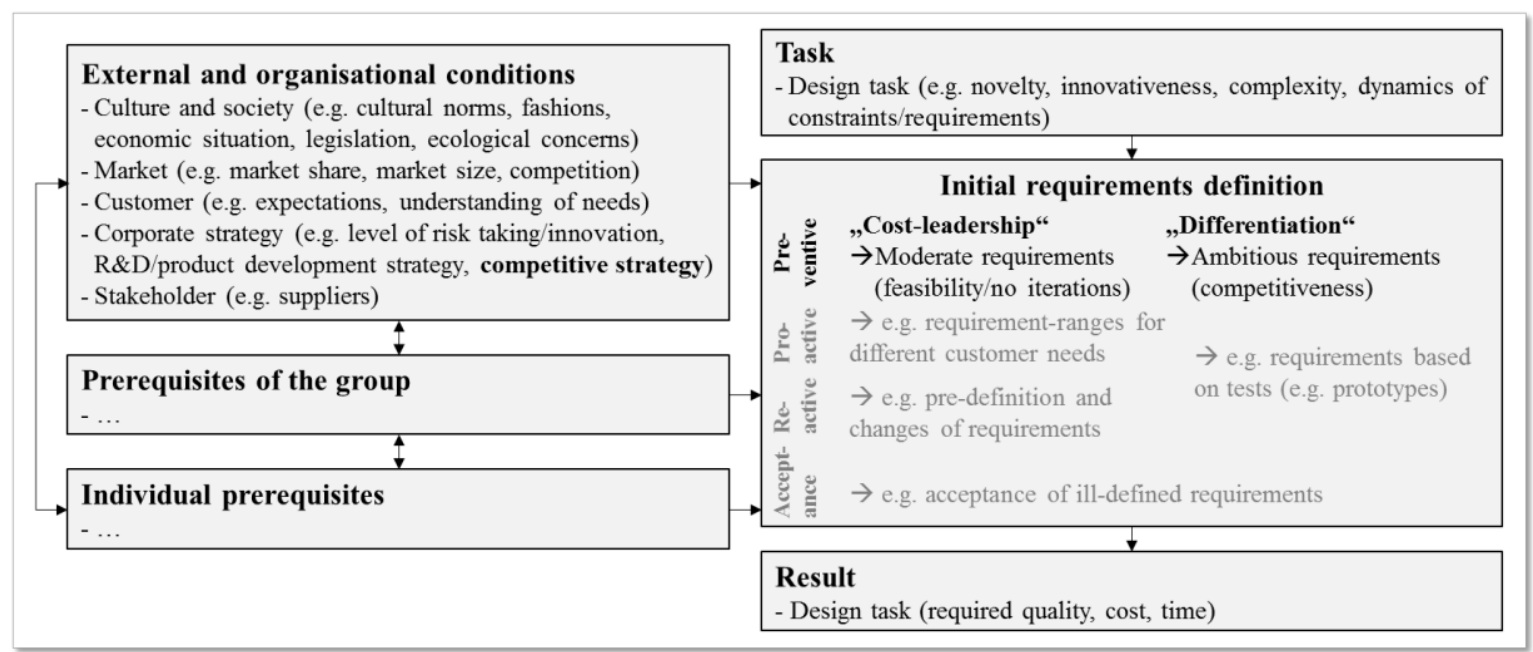

Figure 4. Explanation model/frame for the initial requirements definition

The following sections will exemplify how the initial requirements definition is affected mainly by those influencing and risk-driving context factors in the here presented explanation model/frame.

\subsection{Exemplary cases of initial requirements definition}

The specific process of initial requirements definition depends on the combination of the influencing context factors and their possible characteristics. The following cases merged from (VDI 2221), (Muschik, 2009) and (Song et al., 2018) exemplify, how the processes can be designed dependent on the context. Facing highly competitive markets in each case, both companies pursue a differentiation strategy for new product generations and are willing to take the risks of ambitious requirements. However, there are differences in the way they define initial requirements as described in the following. The differences are summarised in figure 5 and analysed in section 3.3.

\section{Case 1 refers to an automotive manufacturer.}

Cars are complex products that are highly influenced by exogenous constraints like changing regulations, trends, technologic innovations and changes in competition. In order to stay competitive, it is crucial to analyse these constraints and predict their development on a long term and as early as possible. So, this is the first activity when defining initial requirements for a new car concept. The second activity aims at developing product strategies as well as managing and developing new technologies/innovations (endogenous constraints). The third activity concerns the integration of the exogenous and endogenous constraints and derive initial requirements which describe a profile of main product parameters, such as performance, package, weight and fuel consumption as well as planned technologies. It thereby specifies the car's strategic position in its future competitive environment. (Muschik, 2009; VDI 2221)

\section{Case 2 was investigated in a machine tool manufacturer.}

Due to the lower product complexity, machine tool manufacturers face an even higher competition, especially in the low-price segment. Differentiation, for example through particularly high-quality functionality, is therefore still associated with high cost pressure. In order to maintain its technological leadership, the case company established continuous research and development of the core technologies independent of specific product development projects. In case of a new product development, the marketing department formulates product-targets based on an analysis of market trends. Before the actual development begins, the technical departments must assess the general feasibility in a predevelopment phase to confirm or negotiate these initial requirements (Song et al., 2016; VDI 2221).

\subsection{Discussion of the exemplary cases}

Figure 5 summarises the differences in the characteristics of the context factors and in the procedures of the initial requirements definition of both cases. Both companies aim at a differentiation from low-cost competitors and hence tend to define very ambitious requirements. But especially differences in the influence of macroeconomic constraints and in the complexity and technologic innovation potential of the products lead to different strategies in their procedure for initial requirements definition to handle the associated risks. 


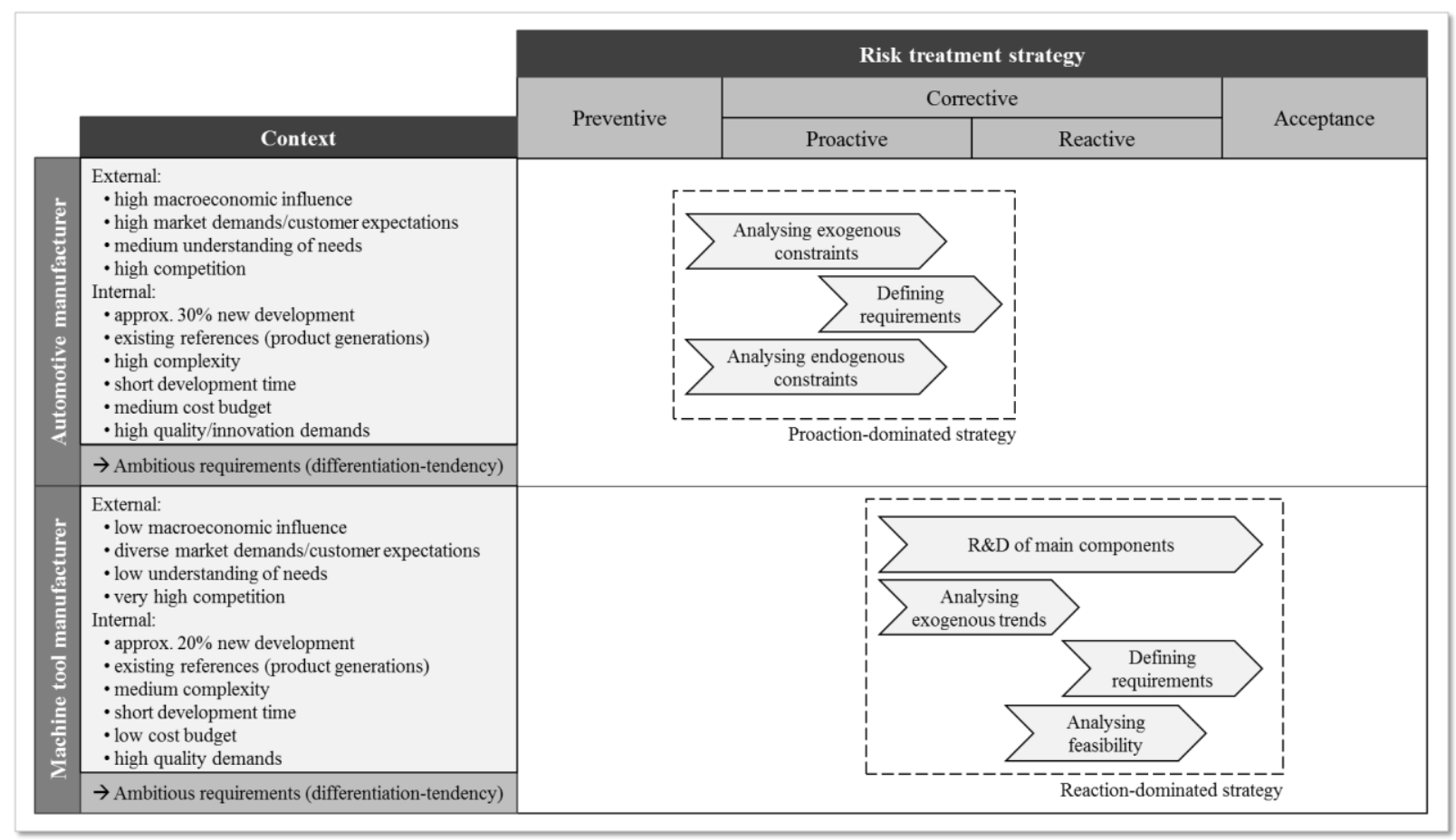

Figure 5. Exemplary cases with significant context factors and their processes for the definition of initial requirements

\section{Context and risk-oriented interpretation of both procedures}

The procedure of the automotive manufacturer is interpreted as a predominantly proactive treatment strategy. High dynamics induced by changes in the macroeconomic (e.g. legislation or ecologic concerns) and microeconomic context (e.g. new competitors) as well as short innovation cycles (e.g. alternative motors or new potentials of automated driving) lead to many possible product scenarios. The requirements definition to describe these scenarios is conducted as early as possible resulting in lead time of several years, which is associated with very high uncertainties regarding the actual required product characteristics far in the future. Therefore, developments in the exogenous and endogenous constraints are analysed and assessed proactively to define initial requirements that describe potential car profiles. The process steps are mainly parallel. Due to the high complexity, changes in the product design are very expensive. Therefore, exogenous and endogenous constraints are analysed intensively in parallel to be compared before defining the initial requirements.

The machine tool manufacturer's procedure is interpreted to follow a mainly reactive treatment strategy. The market is highly competitive as well, but not very dynamic since innovation cycles are not as fast as in the other case and the product is less affected by macroeconomic changes. Therefore, much less development scenarios have to be considered when defining the initial requirements. A proactive analysis and assessment of possible developments would be too resource-consuming. This is why the process design consists of two sequential main phases. Independent from a new project, the case company invests continuously in research and development to constantly improve their main technologies. For new products the degree of new development is assessed low with $20 \%$ compared to a previous product generation. Considering both, the continuous $R \& D$ and low degree of required new development, the risk of not being able to realise the requirements predefined by the marketing is relatively low. So, the analysis of the exogenous and endogenous constraints can be conducted sequentially.

\section{CONCLUSION AND OUTLOOK}

The goal of this paper is to contribute to a better understanding of the initial requirements definition in the early stage of product development. Despite this task is characterised as a decision process under highest uncertainties, support by means of detailed descriptions, explanations or guidelines is missing in the product development literature. This paper presents a conceptual approach to an explanation model/frame for the definition of initial requirements, that establishes a link between the development context and risk-orientation in the procedure (sect. 3.1). The given explanations indicate that the 
integration of risk management is necessary to handle the high uncertainties in this early stage. The first step in this direction is proposed by basing the process and the decision on general risk treatment strategies (sect. 2.2). The comparison of both cases in sect. 3.3 shows that differences in the procedure can be traced back on different characteristics of significantly influencing context factors.

The overarching goal of our research is the identification of typical development contexts and appropriate risk-oriented strategies and process steps for the definition of initial requirements. This allows to design the own specific procedure for this critical development situation more systematic and conscious and thereby makes a valuable contribution to research, education and practice. But despite we reduced the context factors to 29 , this amount is still too much for a detailed investigation. The next step will be to narrow down the context factors to a reasonable amount and the selection and conduction of appropriate case studies. The findings of this paper then serve to develop a theoretical sensitivity for the conception and conduction of the case studies. It will help to separate the important from the unimportant data not only during the conduction, but particularly in the final analysis of the case studies. Furthermore, the application of requirements engineering methods will be analysed to support their selection depending on the context and strategy/process steps of the initial requirements definition.

\section{REFERENCES}

Ahrens, G. (2000), Das Erfassen und Handhaben von Produktanforderungen, PhD thesis, TU Berlin.

Albers, A., Ebel, B. and Lohmeyer, Q. (2012), "Systems of objectives in complex product development", Ninth International Symposium on Tools and Methods of Competitive Engineering, TMCE.

Albers, A., Bursac, N. and Wintergerst, E. (2015), "Product generation development - importance and challenges from a design research perspective", New developments in mechanics and mechanical engineering, pp. 16-21.

Albers, A., Radimersky, A. and Ott, S. (2016), "Systematic definition of objectives for battery systems considering the interdependencies in electric vehicles", AIMS ENERGY, Vol. 4 No. 5, pp. 723-741.

Badke-Schaub, P. and Frankenberger, E. (2004), Management Kritischer Situationen, VDI-Buch. Springer, Berlin, Heidelberg. https://doi.org/10.1007/978-3-642-18702-5_5.

Blessing, L. and Chakrabarti, A. (2009), DRM. A Design Research Methodology, Springer-Verlag, London. https://doi.org/10.1007/978-1-84882-587-1.

Brandenburg, F. and Spielberg, D. (1998), "Implementing New Ideas into R\&D-Strategies - Innovation Management for the Automotive Industry", 31st ISATA, Advanced Manufacturing in the Automotive Industry, Düsseldorf.

Browning, T.R. (1998), Modeling and Analyzing Cost, Schedule and Performance in Complex System Product Development, PhD Thesis, Massachusetts Institute of Technology.

Bullinger, H.-J., Fähnrich, K.-P. and Meiren, T. (2003), "Service engineering-methodical development of new service products", International Journal of Production Economics, Vol. 85 No. 3, pp. 275-287. https://doi.org/10.1016/s0925-5273(03)00116-6.

Chakrabarti, A., Morgenstern, S. and Knaab, H. (2004), "Identification and application of requirements and their impact on the design process: a protocol study", Research in engineering design, Vol. 15 No. 1, pp. 22-39.

Cooper, R.G. (2002), Top oder Flop in der Produktentwicklung. Erfolgsstrategien: Von der Idee zum Launch, Wiley-VCH Verlag, Weinheim.

Cross, N. (2000), Engineering Design Methods. Strategies for Product Design, 3rd edition, John Wiley \& Sons, Chichester.

de Weck, O., Eckert, C. and Clarkson, J.P. (2007), “A classification of uncertainty for early product and system design", Proceedings of the International Conference on Engineering Design 2007 (ICED), Paris.

Eckert, C.M., Alink, T. and Albers, A. (2010), "Issue driven analysis of an existing product at different levels of abstraction", Proceedings of the International DESIGN Conference, Dubrovnik.

Engel, C., Tamdijdi, A. and Quadejacob, N. (2008), "Ergebnisse der Projektmanagement Studie 2008 - Erfolg und Scheitern im Projektmanagment. Gemeinsame Studie der GPM Deutsche Gesellschaft für Projektmanagement e.V. und PA Consulting Group".

Ericson, A. and Kastensson, A. (2011), "Exploit and Explore: Two Ways of Categorizing Innovation Projects", Proceedings of the International Conference on Engineering Design 2011, Copenhagen.

Feldhusen, J. and Grote, K.-H. (2013), Pahl/Beitz Konstruktionslehre. Methoden und Anwendung erfolgreicher Produktentwicklung, Springer-Verlag, Berlin, Heidelberg. http://doi.org/10.1007/978-3-642-29569-0.

Gericke, K. (2011), Enhancing Project Robustness: A Risk Management Perspective, PhD thesis, Berlin.

Gericke, K., Meißner, M. and Paetzold, K. (2013), "Understanding the context of product development", Proceedings of the International Conference on Engineering Design, ICED 2013, Seoul.

Hansen, C.T. and Andreasen, M.M. (2007), "Specifications in early conceptual design work", 16th International Conference on Engineering Design, Ecole Central Paris \& The Design Society, pp. 1-12. 
Hastings, D. and McManus, H. (2006), “A Framework for Understanding Uncertainty and its Mitigation and Exploitation in Complex Systems”, IEEE Engineering Management Review, Vol. 34 No. 3, pp. 81-81.

Ehrlenspiel, K. and Meerkamm, H. (2017), Integrierte produktentwicklung: Denkabläufe, Methodeneinsatz, Zusammenarbeit, 6th edition, Carl Hanser Verlag GmbH Co KG.

Eiletz, R. (1999), Zielkonfliktmanagement bei der Entwicklung komplexer Produkte - am Beispiel PKW Entwicklung, PhD thesis, TU München, Shaker Verlag, Aachen.

Jakoby, W. (2015), Projektmanagement für Ingenieure. Ein praxisnahes Lehrbuch für den systematischen Projekterfolg, Springer Fachmedien Wiesbaden, 3. Aufl. Wiesbaden.

Jarratt, T., Eckert, C., Caldwell, N.H.M. and Clarkson, P.J. (2011), "Engineering Change: an overview and perspective on the literature", Research Engineering Design, Vol. 22, pp. 103-124.

Kendrick, T. (2015), Identifying and managing project risk: Essential tools for failure-proofing your project, 3rd ed., Amacom American Management Association.

Maffin, D. (1998), "Engineering Design Models: context, theory and practice", Journal of Engineering Design, Vol. 9 No. 4, pp. 315-327.

Meißner, M., Gericke, K. and Gries, B. (2005), "Eine adaptive Produktentwicklungsmethodik als Beitrag zur Prozessgestaltung in der Produktentwicklung", In: H. Meerkamm, (Ed.), Design for X, Neukrichen, pp. 67-77.

Muschik, S. (2011), Development of Systems of Objectives in Early Product Engineering - Entwicklung von Zielsystemen in der frühen Produktentstehung, PhD thesis, Karlsruher Institut für Technologie.

Neumann, M. (2017), Ein modellbasierter Ansatz zur risikoorientierten Entwicklung innovativer Produkte, PhD thesis, Ruhr-Universität Bochum.

Neumann, M. and Bender, B. (2016), "Risk-oriented development of innovative products: a model-based approach", Proceedings of NordDesign, pp. 350-359.

Nidamarthi, S., Chakrabarti, A. and Bligh, T.P. (1997), “The significance of co-evolving requirements and solutions in the design process", Proceedings of the International Conference on Engineering Design (ICED97), Tampere, 1, pp. 227-230.

Oehmen, J., Ben-Daya, M., Seering, W. and Al-Salamah, M. (2010), "Risk management in product design: Current state, conceptual model and future research", ASME 2010 International Design Engineering Technical Conferences and Computers and Information in Engineering Conference, pp. 1033-1041.

Oehmen (2016), "Risiko- und Chancenmanagement in der Produktentwicklung", In: U. Lindemann, (Ed.), Handbuch Produktentwicklung, Carl Hanser Verlag GmbH Co KG.

Pahl, G., Beitz, W., Feldhusen, J. and Grote, K.-H. (2007), Engineering design: A systematic approach, 3rd ed., Springer Science \& Business Media, London.

Patzak, G. and Rattay, G. (2018), Projektmanagement: Leitfaden zum Management von Projekten, Projektportfolios, Programmen und projektorientierten Unternehmen, 7th, ed., Linde Verlag GmbH.

Porter, M.E. (1997), “Competitive Strategy”, Measuring Business Excellence, Vol. 1 No. 2, pp. $12-17$. https://doi.org/10.1108/eb025476.

Reymen, I. (2001), Improving design processes through structured reflection: A domain-independent approach, Technische Universiteit Eindhoven.

Rietiker, S., Scheurer, S. and Wald, A. (2013), "Mal andersrum gefragt: Ergebnisse einer Studie zu Misserfolgsfaktoren in der Projektarbeit", Projekt Management, Vol. 2013 No. 4, pp. 33-39.

Salado, A. and Nilchiani, R. (2016), "The concept of order of conflict in requirements engineering", IEEE Systems Journal, Vol. 10 No. 1, pp. 25-35. http://doi.org/10.1109/JSYST.2014.2315597.

Smith, P.G. and Merritt, G.M. (2002), Proactive Risk Management-Controlling Uncertainty in Product Development, Productivity Press, New York, USA.

Song, Y.-W., Windheim, M. and Bender, B. (2018), "Challenges in the definition and prioritisation of requirements: A case study", DS92: Proceedings of the DESIGN 2018 15th International Design Conference, pp. 1337-1344.

Stockstrom, C. and Herstatt, C. (2002), "Planning and uncertainty in new product development", $R \& D$ Management, Vol. 38 No. 2002, pp. 480-490. http://doi.org/10.1111/j.1467-9310.2008.00532.x.

Sudin, M.N. and Ahmed-Kristensen, S. (2011), "Change in requirements during the design process", DS 68-10: Proceedings of the 18th International Conference on Engineering Design (ICED 11), Impacting Society through Engineering Design, Vol. 10: Design Methods and Tools pt. 2, Lyngby/Copenhagen, Denmark.

Ulrich, K.T. and Eppinger, S. (1995), Product Design and Development, McGraw-Hill Inc., Singapore.

Vajna, S. (2014), Integrated Design Engineering. Ein interdisziplinäres Modell für die ganzheitliche Produktentwicklung, Springer Vieweg. http://doi.org/10.1007/978-3-642-41104-5.

VDI 2221 (2018), “Blatt 2”, Entwicklung technischer Produkte und Systeme - Gestaltung individueller Produktentwicklungsprozesse, Beuth Verlag, Berlin.

Winkler, H. and Slamanig, M. (2009), "Generische und hybride Wettbewerbsstrategien im Überblick". WiStWirtschaftswissenschaftliches Studium, Vol. 38 No. 11, pp. 546-552.

Wyatt, D.F., Eckert, C.M. and Clarkson, P.J. (2009), "Design of product architectures in incrementally developed complex products”, Proceedings of International Conference on Engineering Design ICED'09. 